\title{
Perceptions of hand hygiene amongst health care workers in Sibu, East Malaysia
}

\author{
Melanie Birks' ${ }^{1}$, Meaghan Coyle ${ }^{2}$, Joanne Porter ${ }^{2}$, Jane Mills ${ }^{3}$
}

1. Learning and Teaching Education Research Centre, School of Nursing and Midwifery, Central Queensland University, Noosa Campus, QLD, Australia

2. School of Nursing and Midwifery, Monash University, Gippsland Campus, Vic, Australia

3. School of Nursing, Midwifery \& Nutrition, James Cook University, QLD, Australia

\begin{abstract}
The importance of hand hygiene in preventing the spread of disease is universally accepted. Nonetheless, many health care professionals are not always vigilant in carrying out hand hygiene. We studied perceptions of hand hygiene amongst health care professions in the unique location of Sibu, East Malaysia. A modified World Health Organisation questionnaire was used to gather data that was subjected to descriptive analytical techniques. Research participants recognised the importance of performing hand hygiene both for themselves and others. They rated a number of activities of particular value in promoting hand hygiene, reinforcing those described in the literature. These findings provide a foundation for future studies on hand hygiene.
\end{abstract}

Key words

HYGIENE; HAND-microbiology; HAND WASHING; HEALTH PERSONNEL

\section{Introduction}

Despite the emphasis placed on hand washing and related hygiene activities, many health care professionals still fail to adhere to this basic practice. As part of a project funded by an Australian
Government grant, we surveyed nurses and health care professionals employed in the East Malaysian health care environment to ascertain their perceptions of hand hygiene practices.

\footnotetext{
Corresponding author

Dr Melanie Birks

Associate Professor, Learning and Teaching Education Research Centre, School of Nursing and Midwifery, Central Queensland University, Noosa Campus, QLD, Australia

Email: m.birks@cqu.edu.au
} 


\section{Background}

The most important factor in preventing the spread of illness is the performance of hand hygiene. ${ }^{1}$ Most health care professionals recognise this and yet compliance is usually $<50 \%{ }^{2}$ The literature suggests that compliance is related to access to resources, ${ }^{2-5}$ sociocultural factors, ${ }^{3-5}$ education ${ }^{4,} 6$ along with attitude and role modelling. ${ }^{2,7}$ Tai et al. ${ }^{6}$ suggested that having local data is imperative to ensure strategies to improve hand hygiene are relevant to the setting. No such research has been conducted in East Malaysia and so this paper reports on a survey undertaken in this location and its contribution to existing knowledge.

\section{Methods}

Before the study began, approval was obtained for its conduct from the University ethics committee. The sample consisted of participants from the East Malaysian state of Sarawak attending a seminar for nurses and health care professionals in the city of Sibu. Participation was voluntary; respondents were furnished with an explanatory statement and a verbal explanation of the research with any potential risk to their wellbeing. This study employed a quantitative survey design. Permission was obtained from the World Health Organisation to use their hand hygiene questionnaire to explore participants' perceptions of hand hygiene. ${ }^{8}$ The survey was modified to remove irrelevant items (e.g. institutional data) and amend terminology to reflect that used in the local environment.

The questionnaire was administered on the first morning of a two-day seminar that aimed to develop basic skills in research for health professionals. Consent was implied by return of the questionnaire. As the purpose of the seminar was to enhance the ability of nurses and other health care professionals to be involved in research, data was analysed during the seminar and a draft of the paper written up in real-time over a series of workshop activities reported elsewhere. ${ }^{9}$ Data was collated and entered into a Microsoft Excel ${ }^{\circledR}$ spreadsheet, and subjected to descriptive analysis techniques.

\section{Results}

One hundred and forty two of the 146 attendees returned the survey; a response rate of $97.3 \%$. Almost all respondents were female $(98.6 \%)$, reflecting the predominantly female nature of the profession. Their mean age was 37.3 years. Most were registered nurses $(78.2 \%)$ with community nurses (12.7\%), midwives $(7 \%)$, doctors $(0.7 \%)$, therapists $(0.7 \%)$ and others $(0.7 \%)$. Many worked in medical/surgical units $(32.4 \%)$ and midwifery units (17.6\%). Others worked in paediatrics, emergency departments, outpatients, operating theatres, long term rehabilitation and elsewhere.

Most respondents (85.2\%) had undertaken formal training in hand hygiene in the last 3 years, and $91.5 \%$ routinely used alcohol based handrubs. Table I shows that, participants responding to a 5 point Likert scale believed hand hygiene to be either 'extremely' or 'very' important, and also felt it held similar importance for management, colleagues and patients. Only one respondent perceived that hand hygiene was 'not important' in relation to management.

Participants were asked how effective they felt particular actions would be in improving hand hygiene permanently in their institution. While all

Table I. Perceptions of importance of hand hygiene (n \%)

\begin{tabular}{lrrrrr}
$\begin{array}{l}\text { How important is hand } \\
\text { hygiene }(\mathbf{n = 1 4 2 )}\end{array}$ & $\begin{array}{r}\text { Not } \\
\text { important }\end{array}$ & $\begin{array}{r}\text { Slightly } \\
\text { important }\end{array}$ & $\begin{array}{r}\text { Moderately } \\
\text { important }\end{array}$ & $\begin{array}{r}\text { Very } \\
\text { important }\end{array}$ & $\begin{array}{r}\text { Extremely } \\
\text { important }\end{array}$ \\
\hline To you & $0(0)$ & $0(0)$ & $0(0)$ & $31(21.8)$ & $111(78.2)$ \\
\hline To management & $1(0.7)$ & $0(0)$ & $3(2.1)$ & $48(33.8)$ & $90(63.4)$ \\
\hline To colleagues $(\mathrm{n}=140)$ & $0(0)$ & $0(0)$ & $1(0.7)$ & $43(30.7)$ & $96(68.6)$ \\
\hline To patients & $0(0)$ & $2(1.4)$ & $2(1.4)$ & $34(23.9)$ & $104(73.2)$ \\
\hline
\end{tabular}


Table II. Strategies participants perceived would be 'very effective' in improving hand hygiene practices (n \%)

\section{How effective would the following be to improve hand hygiene in your institution? $(n=142)$}

\begin{tabular}{rrrrr}
$\begin{array}{r}\text { Very } \\
\text { ineffective }\end{array}$ & $\begin{array}{r}\text { Moderately } \\
\text { ineffective }\end{array}$ & Unsure & $\begin{array}{r}\text { Moderately } \\
\text { effective }\end{array}$ & $\begin{array}{r}\text { Very } \\
\text { effective }\end{array}$ \\
\hline $0(0)$ & $1(0.7)$ & $2(1.4)$ & $39(27.7)$ & $99(70.2)$
\end{tabular}

\begin{tabular}{l}
$\begin{array}{l}\text { Perform hand hygiene as recommended } \\
(\mathrm{n}=141)\end{array}$ \\
\hline
\end{tabular}

\begin{tabular}{lccccc}
$\begin{array}{l}\text { Receive education on hand hygiene } \\
(\mathrm{n}=140)\end{array}$ & $0(0)$ & $0(0)$ & $6(4.3)$ & $36(25.7)$ & $98(70.0)$ \\
\hline Handrub always available & $1(0.7)$ & $4(2.8)$ & $0(0)$ & $43(30.3)$ & $94(66.2)$ \\
\hline \begin{tabular}{l} 
Instructions visible $(\mathrm{n}=140)$ \\
\hline Posters displayed $(\mathrm{n}=140)$
\end{tabular} & $1(0.7)$ & $0(0)$ & $3(2.1)$ & $44(31.4)$ & $92(65.7)$ \\
\hline $\begin{array}{l}\text { Feedback provided }(\mathrm{n}=140) \\
1(0.7)\end{array}$ & $1(0.7)$ & $4(2.9)$ & $50(35.7)$ & $84(60.0)$ \\
\hline Managers promote hand hygiene & $1(0.7)$ & $2(1.4)$ & $7(5.0)$ & $48(34.3)$ & $82(58.6)$ \\
\hline Patients remind staff $(\mathrm{n}=140)$ & $1(0.7)$ & $5(3.5)$ & $4(2.8)$ & $49(34.5)$ & $83(58.5)$ \\
\hline
\end{tabular}

eight activities presented in the survey were perceived as being 'very effective' (Table II), actually performing hand hygiene practices as recommended was itself seen to be an important reinforcing factor, particularly given its potential for positive role modelling. Education was also a significant factor. The strategy participants thought would be least effective in improving hand hygiene was that of patients reminding health care workers to perform hand hygiene.

\section{Discussion}

These findings provide some interesting data about the perceptions of health care professionals. Like those of both Jumaa ${ }^{4}$ and Yuan et al. ${ }^{5}$ they suggest that participants are aware of the importance of proper hand hygiene practice. The high number of our participants who indicated personal compliance with hand hygiene practices is of interest. Possibly their perceptions reflect the comments by Cookson et al. ${ }^{7}$ that health care professionals overestimate how often they actually perform hand hygiene during the working day.
The top factors identified by participants for improving hand hygiene practices related to guidelines, education and resources; themes that run throughout the literature on this topic. Continued use of promotional and instructional materials was also considered useful for reminding staff of the need to perform hand hygiene. Our respondents also suggested that promotion of a positive culture, led by management, would ensure continual presentation of role models and feedback to support good practice, reinforcing similar suggestions by Cookson et al. ${ }^{7}$

Although not rated as highly as other factors, interestingly enough a high percentage of the participants believed that hand hygiene would be more effective if patients reminded the health worker to wash their hands. The relatively lower rating of this factor may reflect cultural perceptions of the acceptability of 'shaming' the health care professional. While our respondents came from a broad range of clinical units, the use of a relatively small convenience sample and a single location are limitations of this 
research. Furthermore, reliance on self-reporting restricts the objectivity of the data and a study employing observation may provide more reliable data.

\section{Conclusion}

As caring professionals, health care workers seek to protect others and ensure the wellbeing of patients and co-workers. Although a simple measure in preventing the spread of disease, the literature suggests that hand hygiene practices are not always undertaken in accordance with universally accepted standards. This paper has provided an overview of the perceptions of health care workers in relation to hand hygiene, providing a foundation for further work in evaluating and promoting this important infection control measure.

\section{Acknowledgment}

The authors wish to acknowledge with thanks the nurses and other health care professionals attending the Sarawak Midwives Association/Sibu Hospital Research Seminar in Sibu, East Malaysia in October 2010, who were enthusiastic participants in this event and the research reported in this paper. The contribution of the Australia Malaysia Institute in funding this project is also gratefully acknowledged.

\section{References}

1. CDC. Wash your hands. In: Centres for Disease Control and Prevention; 2010.

2. Pittet D, Simon A, Hugonnet S, Pessoa-Silva CL, Sauvun V, Perneger TV. Hand hygiene among physicians: Performance, Beliefs, and Perceptions. Annals of Internal Medicine 2004; 141: 1-8.

3. Borg MA, Benbachir M, Cookson BD, et al. Health care worker perceptions of hand hygiene practices and obstacles in a developing region. American Journal of Infection Control 2009; 37: 855-857. http://dx.doi.org/10.1016/j. ajic.2009.06.003

4. Jumaa PA. Hand hygiene: Simple and complex. International Journal of Infectious Diseases 2005; 9: 3-14. http://dx.doi. org/10.1016/j.ijid.2004.05.005

5. Yuan CT, Dembry LM, Higa B, Fu M, Wang H, Bradley EH. Perceptions of hand hygiene practices in China. Journal of Hospital Infection 2009; 71: 157-162. http://dx.doi. org/10.1016/j.jhin.2008.09.017

6. Tai J, Mok E, Ching P, Seto W, Pittet D. Nurses and physicians' perceptions of the importance and impact of health-care associated infections and hand hygiene: a multi-center exploratory study in Hong Kong. Infection 2009; 37: 320333. http://dx.doi.org/10.1007/s15010-009-8245-x

7. Cookson B, French G, Gould D, et al. Handwashing: A modest measure - with big effects. British Medical Journal 1999; 318: 686.

8. World Health Organisation. Perception Survey for HealthCare Workers (revised August 2009). In: World Health Organisation; 2009.

9. Birks. Making it real: A hands-on approach to teaching research. International Nursing Review 2011. 